\title{
Air- $Q$ Intubating Laryngeal Airway with Proseal Laryngeal Mask Airway in Elective Surgeries- A Comparative Study
}

\author{
Neeraj ${ }^{1}$, Archana Agarwal ${ }^{2}$ \\ ${ }^{1}$ Associate Professor, GS Medical College, Pilkhuwa, Hapur, ${ }^{2}$ Assistant Professor, GS Medical College \& Hospital, Pilkhuwa.
}

\section{Abstract}

Background: The present study was conducted to compare Air- Q intubating laryngeal airway with ProSeal laryngeal mask airway. Subjects and Methods: The present study was conducted on 84 patients of ASA grade I and II for surgery. Patients were divided into 2 groups of 42 each. Group I patients were given ProSeal laryngeal mask airway and group II were given Air-Q intubating laryngeal airway. All the devices were checked, prepared, inserted and secured according to the corresponding manufacturer's recommendations. Results: The mean airway time in group I was 17.2 seconds and in group II was 18.4 seconds, airway seal pressure (cm H2O) in group I was 25.3 and in group II was 23.1, use of jaw thrust was 6 in group I and 9 in group II, number of attempts were 1 in each group. The difference was non- significant (P> 0.05). Conclusion: Both PLMA and AQB show similar efficacy in maintaining ventilation and oxygenation, during procedures.

Keywords: Airway, Air- Q intubating laryngeal airway, ProSeal laryngeal mask.

Corresponding Author: Dr Archana Agarwal, Assistant Professor, GS Medical College \& Hospital, Pilkhuwa.

Received: September 2019

Accepted: September 2019

\section{Introduction}

Managing airway is one of the most important skills to master in the anesthesia profession. Supraglottic airway devices (SAD) are being routinely used in airway management, filling a niche between the face mask and tracheal tube in terms of both anatomical position and degree of invasiveness. ${ }^{[1]}$

The ProSeal laryngeal mask airway (PLMA) besides having all the inherent qualities of Classic laryngeal mask airway offers several advantages over it. ${ }^{[2]}$ It has an additional drain tube running parallel to the airway tube that prevents inadvertent gastric inflation and permits access to the gastrointestinal tract through the drainage tube (gastric tube), thereby attributing to increased safety when used with positive pressure ventilation. Proseal laryngeal mask airway (LMA), introduced in 1999 is being widely used for airway management in general anesthesia with controlled as well as spontaneous ventilation. It is designed to conform to the contours of the hypo pharynx, with its lumen facing the laryngeal opening. ${ }^{[\beta]}$

The Air-Q intubating laryngeal airway has gained wide acceptance. The Air-Q Blocker (AQB) is a novel LMA of Air-Q series which is useful in emergency medical services. It has all the distinct "rescue" airway requirements including advantages for intubation and managing the esophagus. The newer device AQB is a supraglottic device designed as a primary ventilation airway which in addition has a conduit for endotracheal intubation and has the ability to place the drainage tube (esophageal blocker tube/gastric tube) via a specific integrated blocker channel. ${ }^{[4]}$ The present study was conducted to compare Air- Q intubating laryngeal airway with ProSeal laryngeal mask airway.

\section{Subjects and Methods}

The present study was conducted in the department of Anesthesiology. It comprised of 84 patients of ASA grade I and II for surgery. The study was approved from the institutional ethical committee. All were informed regarding the study and written consent was obtained.

Data such as name, age, gender etc. was recorded. Patients were divided into 2 groups of 42 each. Group I patients were given Pro Seal laryngeal mask airway and group II were given Air-Q intubating laryngeal airway. All the devices were checked, prepared, inserted and secured according to the corresponding manufacturer's recommendations. In both groups, insertion times, number of insertion attempts, hemodynamic response to insertion, ease of insertion of airway device and gastric tube, oropharyngeal leak pressure (OLP) and pharyngolaryngeal morbidity were assessed. Results thus obtained were subjected to statistical analysis. $\mathrm{P}$ value less than 0.05 was considered significant.

Results

Table I Distribution of patients

\begin{tabular}{|l|l|l|}
\hline Groups & Group I (PLMA) & Group II (Air- Q) \\
\hline Number & 42 & 42 \\
\hline
\end{tabular}


[Table 1] shows that group I patients were given ProSeal laryngeal mask airway and group II were given Air-Q intubating laryngeal airway.

Table 2: Comparison of airway parameters

\begin{tabular}{|l|l|l|l|}
\hline Parameters & Group I & Group II & P value \\
\hline Airway time (sec) & 17.2 & 18.4 & 0.45 \\
\hline $\begin{array}{l}\text { Airway seal pressure (cm } \\
\text { H2O) }\end{array}$ & 25.3 & & 23.1 \\
\hline Use of jaw thrust & 6 & 9 & 0.71 \\
\hline Number of attempt & 1 & 1 & 0.05 \\
\hline
\end{tabular}

[Table 2] shows that mean airway time in group I was 17.2 seconds and in group II was 18.4 seconds, airway seal pressure (cm H2O) in group I was 25.3 and in group II was 23.1, use of jaw thrust was 6 in group I and 9 in group II, number of attempts were 1 in each group. The difference was non- significant $(\mathrm{P}>0.05)$.

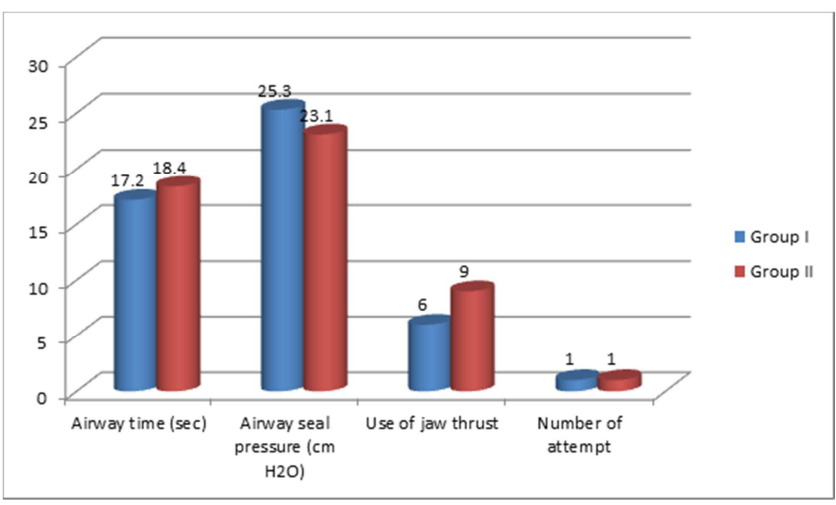

Figure 1: Comparison of airway parameters

\section{Discussion}

Many second-generation SADs now outperform the firstgeneration LMAs in all these domains being as easy or easier to insert, with higher oropharyngeal seal pressures and with design features that are intended to reduce the risk of aspiration. ${ }^{[5]}$ The use of SAD under conditions of elevated intra-abdominal pressure requires an excellent airway seal to divide respiratory and alimentary tract in a reliable manner, due to the potential risk of regurgitation and pharyngeal morbidity. The second-generation supraglottic devices have been proved to be safe in such procedures. ${ }^{[6]}$ Laparoscopic surgery provides the most severe test for efficacy of SAD during positive pressure ventilation and various supraglottic devices have been found to be effective as ventilatory device for laparoscopic cholecystectomy. AQB tube goes approximately 5-6 cm beyond the cuff of the AQB into the pharynx and has its own cuff that after inflation blocks the upper esophagus. This device has been used in various situations for rescue ventilation and also aids in suctioning and venting the esophagus. ${ }^{[7]}$ The present study was conducted to compare Air- Q intubating laryngeal airway with ProSeal laryngeal mask airway.

In this study, Patients were divided into 2 groups of 42 each. Group I patients were given ProSeal laryngeal mask airway and group II were given Air-Q intubating laryngeal airway. Moorthy et al, ${ }^{[8]}$ found that the mean airway seal pressure of Air- Q was lower $(23.95 \pm 1.709 \mathrm{~cm}$ of $\mathrm{H} \square \mathrm{O})$ as compared to
P-LMA (25.53 $\pm 2.07 \mathrm{~cm}$ of $\mathrm{H} \square \mathrm{O})$ which was statistically highly significant. The fibreoptic evaluation of vocal cords revealed grade I/II/III view in 37/2/1 cases of Air-Q and in $1 / 30 / 9$ cases of P-LMA ( $p=0.0001)$.

We found that mean airway time in group I was 17.2 seconds and in group II was 18.4 seconds, airway seal pressure $(\mathrm{cm}$ $\mathrm{H} 2 \mathrm{O}$ ) in group I was 25.3 and in group II was 23.1, use of jaw thrust was 6 in group I and 9 in group II, number of attempts were 1 in each group. Jagannathan et ${ }^{a},{ }^{[9]}$ postulated a seal pressure of at least $20 \mathrm{~cm} \mathrm{H} 2 \mathrm{O}$ in combination with a square wave capnogram to classify an airway to be sufficient. Design features unique to the AirQTM that are likely to improve its airway seal pressure include: (1) an anterior curve of the airway tube that better approximates the upper airway and provides a more stable end-to-end coupling with the glottis; (2) mask ridges that improve the transverse stability of the bowl and support the lateral cuff seal; and (3) a higher posterior heel height, which improves the seal at the base of the tongue.

Gupta et al, ${ }^{[10]}$ found that Oropharyngeal seal pressures for AQB and PLMA were $31.5 \pm 2.41$ and $29.41 \pm 2.14 \mathrm{~cm}$ $\mathrm{H} 2 \mathrm{O}$, respectively $(\mathrm{P}=0.01)$. Insertion time was longer with AQB than PLMA, $25.59 \pm 5.71$ and $18.66 \pm 3.15$ seconds, respectively $(\mathrm{P}=0.001)$. Ease and success rate of insertion was better with PLMA compared to AQB. Failure of device insertion was seen in 2 cases of Group A. Gastric distension was seen in 4 patients in Group A, requiring replacement with endotracheal tube in two patients. Ventilation was successful in all 44 patients with PLMA. Both the devices were comparable in providing a patent airway and adequate oxygenation during controlled ventilation. There was an increased trend of airway trauma and complications in the AQB group.

\section{Conclusion}

Both PLMA and AQB show similar efficacy in maintaining ventilation and oxygenation, during procedures.

\section{References}

1. Tim M Cook, Gene Lee, Jerry P Nolan. The Proseal laryngeal mask airway: A review of the literature. Can J Anesth 2005;52:739-60.

2. R E Galgon, K M Schroeder, S Han, A Andrei, and A M Joffe. The Air-Q intubating laryngeal airway vs the LMA ProSeal: a prospective, randomised trial of airway seal pressure. Anaesth 2011;66:1093-1100.

3. E J Bakker, M Valkenburg, E M Galvin. Pilot study of the Air- Q intubating laryngeal airway in clinical use. Anaesth Intensive Care 2010;38:346-48.

4. Maha M.I. Youssef, Mona Lofty, Yahya Hammad, Ezzat Elmenshawy. Comparative study between LMA-Proseal and Air-Q Blocker for ventilation in adult eye trauma patients. Egypt J Anaesth 2014;30:227-33.

5. Sharifa Ali Sabeeh Al-Rawahi, Haris Aziz, Mohammed Azharuddin Malik. A comparative analysis of the Baska Mask vs Proseal laryngeal mask for general anaesthesia with IPPV. Anaesth Pain Intensive Care 2013;17:233-36

6. Darlong V, Biyani G, Pandey R, Baidya DK., Chandralekha, Punj J. Comparison of performance and efficacy of Air-Q intubating laryngeal airway and flexible laryngeal mask airway in anesthetized and paralyzed infants and children. Paediatr Anaesth 2014;24:1066-71.

7. Jagannathan N, Sohn L, Ramsey M, Huang A, Sawardekar A, Luis Sequera-Ramos et al. A randomized comparison between the i-gel and the air-Q supraglottic airways when used by anesthesiology trainees as conduits for tracheal intubation in children. Can J Anaesth 2015;62:58794. 
8. Moorthy PVC, Desai D, Upadhyay MR. Comparison of the Air-Q intubating laryngeal airway with the Proseal laryngeal mask airway in elective surgeries: A randomized controlled study. Indian J Clin Anaesth 2019;6(3):349-54.

9. N Jagannathan, L E Sohn, R Mankoo, K E Langen, and T Mandler. A randomized crossover comparison between the laryngeal mask airway- unique and the air-Q intubating laryngeal airway in children. Paediatr Anaesth 2012;22:161-7.

10. Gupta R, Mahajan R, Jatinder M, Gulati S, Mehta A, Nazir R. A comparison between ProSeal laryngeal mask airway and Air-Q Blocker in patients undergoing elective laparoscopic cholecystectomy. J Anaesthesiol Clin Pharmacol 2019;35:340-7.

Copyright: () the author(s), publisher. Academia Anesthesiologica International is an Official Publication of "Society for Health Care \& Research Development". It is an open-access article distributed under the terms of the Creative Commons Attribution Non-Commercial License, which permits unrestricted non-commercial use, distribution, and reproduction in any medium, provided the original work is properly cited.

How to cite this article: Neeraj, Agarwal A. Air- Q Intubating Laryngeal Airway with Proseal Laryngeal Mask Airway in Elective SurgeriesA Comparative Study. Acad. Anesthesiol. Int. 2019;4(2):329-31.

DOI: dx.doi.org/10.21276/aan.2019.4.2.74

Source of Support: Nil, Conflict of Interest: None declared. 